\title{
QUALIDADE DAS OPERAÇÕES DE PREPARO DE SOLO POR CONTROLE ESTATÍSTICO DE PROCESSO
}

\author{
Marcos Milan ${ }^{1 *}$; Ricardo Alves Thomaz Fernandes² \\ ${ }^{1}$ Depto. de Engenharia Rural - USP/ESALQ - C.P. 9 - CEP: 13418-900 - Piracicaba, SP. \\ ${ }^{2}$ Pós-Graduando em Máquinas Agrícolas - USP/ESALQ. \\ *Autor correspondente <macmilan@carpa.ciagri.usp.br>
}

RESUMO: A concorrência em escala mundial obriga as empresas a buscar maior eficiência administrativa e operacional. As técnicas de controle estatístico de processo (CEP) são uma das ferramentas que permitem a melhoria da qualidade e produtividade nas empresas. Desenvolvido e largamente aplicado nas indústrias, 0 CEP tem grande potencial de utilização na agropecuária. Tendo em vista o desenvolvimento desse potencial, esse trabalho tem por objetivo avaliar os efeitos da utilização do controle de qualidade em operações agrícolas de preparo do solo para a cultura do milho utilizando-se como ferramenta de análise o CEP. A utilização do controle na operação de escarificação proporcionou redução da variabilidade de dados de profundidade de trabalho média em $38,4 \%$ e aumento de $45,0 \%$ dos dados desejados. Na gradagem, houve redução de $9,8 \%$ dos dados médios de tamanho de torrões, e um aumento de $75,0 \%$ de torrões aceitáveis.

Palavras-chave: Zea mays, mecanização, máquinas agrícolas, implemento

\section{QUALITY OF TILLAGE OPERATIONS BY STATISTICAL PROCESS CONTROL}

\begin{abstract}
Agricultural enterprises must have a professional business management and competitive operational techniques to face competition. The statistical process control (SPC) technique is one of the tools that improve quality and productivity of the companies. Developed and used in factories, the SPC has a large application potential for farming and stocking. Facing this potential development, the aim of this study was to evaluate the quality control effects on tillage operations using the SPC as an evaluation tool. The quality control for the chisel operation provided a reduction of $38.4 \%$ on data average variability and increased desired data to $45.0 \%$. For the harrow operation, provided a reduction of $9.8 \%$ of the average diameter, and increased in $75.0 \%$ the desired stone diameter rate for the area.

Key words: Zea mays, mechanization, agricultural machinery, implement
\end{abstract}

\section{INTRODUÇÃO}

Para as empresas, um dos pontos fundamentais para o sucesso é a estabilização dos processos de rotina garantindo a confiabilidade do produto. Uma definição aceita para qualidade é a redução da variabilidade que quanto menor, melhor será a confiabilidade e a aceitação do produto ou serviço. A variabilidade, segundo Montgomery (1996), é sinônimo de desperdício de dinheiro, tempo e esforços

Bonilla (1995) e Montgomery (1996) ressaltam que o controle estatístico de processos é um conjunto de ferramentas úteis para a resolução de problemas para o alcance da estabilidade do processo e aumento da capacidade através da redução da variabilidade.

Aplicando o controle da qualidade em operações mecanizadas na cultura de cana-de-açúcar (Saccharum spp.), Lopes et al. (1995) concluíram que os índices de variação encontrados nas áreas analisadas foram muito elevados. No caso do espaçamento entre sulcos, a variação entre os diversos grupos estudados estava fora de controle, apesar da média estar próxima da desejada para a operação, sugerindo problemas de má regulagem do implemento ou erros na operação.
Fernandes (1997), trabalhando com operações agrícolas mecanizadas de um sistema de produção de cana-de-açúcar (Saccharum spp.), observou que apesar da operação de subsolagem estar sob controle estatístico, encontrava-se com valores de profundidade de trabalho não compatíveis com as especificações da empresa. Em talhões amostrados, denominados A, B e C, apenas $26,7 \%, 26,7 \%$ e $16,0 \%$ dos pontos, respectivamente, encontravam-se dentro do intervalo padrão de 0,45 a $0,50 \mathrm{~m}$ desejado para a operação. A variação de valores encontrada, também foi considerada excessiva, onde o indicador mais baixo foi de $0,43 \mathrm{~m} \mathrm{e}$ o mais alto, 0,61 m.

Avaliando a influência de indicadores de qualidade no custo operacional de um sistema de produção de milho, Dodson (1998) observou que a semeadura encontrava-se fora dos padrões preestabelecidos e apenas $56 \%$ dos valores estavam dentro das especificações (entre 4 e 6 sementes $/ \mathrm{m}$.l.). Além disso, o autor atestou que somente $40 \%$ das sementes estavam dentro do espaçamento horizontal desejado (de 0,20 a 0,33 m entre sementes). Desse modo, a lavoura de milho desenvolveu-se sem uniformidade, com a possibilidade de existirem 
problemas com surgimento de plantas daninhas em espaços não ocupados pela planta de milho. Nos locais com um número excessivo de sementes, a produtividade por área seria reduzida.

Lino et al. (1999), analisando a fragmentação de fitomassa realizada por uma roçadora em área com predominância de capim-colonião, utilizaram ferramentas preconizadas pelo controle estatístico da qualidade. Os autores observaram grande variabilidade da distribuição da fitomassa, cuja média foi de $1.796 \mathrm{~kg} \mathrm{ha}^{-1} \mathrm{e}$ alto coeficiente de variação $(77,54 \%)$. Quanto ao tamanho dos fragmentos, a média encontrada foi de $0,19 \mathrm{~m}$, com a amplitude dez vezes maior do que esse valor; entretanto o coeficiente de variação foi baixo, 19,07\%. Assim, os autores concluíram que a metodologia aplicada foi suficiente e adequada para a caracterização da área antes e depois da operação.

As operações agrícolas de preparo do solo são normalmente realizadas sem que haja um controle efetivo para que a variabilidade das mesmas fiquem dentro de padrões aceitáveis. Com isso, o objetivo deste trabalho é verificar os efeitos do controle de qualidade aplicado a operações de preparo de solo para a cultura do milho, utilizando-se como ferramenta de análise o controle estatístico de processos (CEP).

\section{MATERIAL E MÉTODOS}

A área experimental situou-se na região de Piracicaba (SP), em um argissolo, sendo utilizado para a cultura de milho (Zea mays L.) para silagem.

A área foi dividida em duas parcelas. $\mathrm{Na}$ primeira, denominada de tratamento $A 1$, a operação foi avaliada somente após a execução; na segunda, tratamento $A 2$, realizou-se o controle de variáveis críticas antes e durante a execução. Cada parcela mediu $225 \mathrm{~m}$ por $25 \mathrm{~m}$, totalizando $5.625 \mathrm{~m}^{2}$. Entre elas, foi deixada uma faixa de $20 \mathrm{~m}$ de comprimento para as manobras e paradas do conjunto mecanizado. A área total do experimento foi de $11.750 \mathrm{~m}^{2}$, considerando-se a área para manobras.

Foram escolhidas duas operações agrícolas dentro do sistema de produção, escarificação e gradagem. Definiu-se, em conjunto com os técnicos responsáveis, os limites de especificação dos processos (ou padrão de qualidade) para atender as necessidades da cultura do milho com base em critérios agronômicos. Para a escarificação, adotou-se o intervalo de 0,20 a 0,25 $\mathrm{m}$ de profundidade e para a gradagem o intervalo de 0,0 a $0,04 \mathrm{~m}$ para o diâmetro dos torrões.

Os métodos estatísticos utilizados para ambas as operações foram os histogramas, as cartas de controle por variáveis e o teste $T$. As convenções utilizadas nas cartas de controle foram descritas como limites inferior (LIE) e superior (LSE) de especificação, que correspondem aos critérios agronômicos definidos pelos técnicos. Os limites inferior (LIC) e superior de controle
(LSC) resultam da análise estatística e são determinados de acordo com a variabilidade do processo.

As duas áreas trabalhadas foram divididas em 75 pontos, sendo 15 colunas por 5 linhas, resultando em uma malha retangular e, em cada um desses pontos, foi realizada a amostragem. Para efeito de se construir a carta de controle, cada 5 pontos de uma mesma coluna correspondem a um grupo de amostra.

A escarificação, nas duas áreas de tratamento, foi realizada no dia 18 de dezembro de 1999 utilizandose de um trator da marca Massey Ferguson $2964 \times 2 \mathrm{e}$ um escarificador STARA, de 5 hastes, espaçadas a 0,30 $\mathrm{m}$, regulado para operar a $0,25 \mathrm{~m}$ de profundidade. A amostragem dos dados foi realizada com um penetrômetro hidráulico, de marca Dickey-john, o qual foi introduzido no solo em cada um dos 75 pontos da malha. Como critério para determinar a profundidade de preparo, foi estabelecida a linha que divide a escala verde, no manômetro ( sem restrições ao desenvolvimento da raiz, de acordo com o manual do equipamento), da amarela (restrição moderada) o que corresponde a $1372 \mathrm{kPa}$. Pelo fato de se usar o penetrômetro como um dispositivo para inferir a profundidade de preparo e não a resistência a penetração, não foi realizada a amostragem do teor de água do solo.

Com os dados do tratamento $A 1$, foram sugeridas e realizadas mudanças no modo de trabalho no campo antes do início em A2 envolvendo o alinhamento dos discos cortadores de palha do implemento, os quais estavam desalinhados das hastes do escarificador; ajuste e checagem constante da profundidade durante a operação e a redução da velocidade de trabalho do trator, visando melhorar a penetração do implemento no solo.

Foram realizadas duas gradeações, no dia 27 de dezembro de 1999, nos tratamentos A1 e A2. Uma com grade de 32 discos com $0,51 \mathrm{~m}$ de diâmetro $(32 \times 20$ ") e outra de 14 discos de $0,66 \mathrm{~m}$ de diâmetro ( $14 \times 26$ "), tracionadas pelos tratores Valtra/Valmet $885 \mathrm{~S} 4 \times 2 \mathrm{e}$ Massey Ferguson $2754 \times 2$ TDA, respectivamente. A amostragem dos dados referentes ao tamanho dos torrões, em cada um dos 75 pontos da malha, foi realizada com um dispositivo, apresentado na Figura 1.

O dispositivo, no formato de um quadrado com $0,71 \mathrm{~m}$ de lado, correspondendo a uma área de $0,5 \mathrm{~m}^{2}$, contem em três de seus vértices, pequenos quadrados para a realização da comparação visual com os torrões. O menor, com 0,004 m de lado, corresponde ao tamanho desejado pelo corpo técnico; o médio com $0,007 \mathrm{~m}$ ao padrão aceitável e o maior, com 0,009 m considerado como inaceitável. O dispositivo lançado ao acaso sobre o solo permite a classificação visual dos torrões existentes na área delimitada pelo quadrado.

Anteriormente ao início da operação de gradagem no tratamento $A 2$, foram sugeridas e realizadas mudanças no modo de trabalho no campo, após uma conferência dos dados coletados em A1: 
limpeza dos discos das grades; reaperto dos parafusos dos mancais e da barra porta-ferramentas das grades; alteração da velocidade de trabalho. Em A1 a velocidade foi $1,18 \mathrm{~m} \mathrm{~s}^{-1}$ com a grade $32 \times 20$ " e $1,04 \mathrm{~m} \mathrm{~s}^{-1}$ com a grade $14 \times 26$ ". Em A2 as velocidades foram de $1,48 \mathrm{~m} \mathrm{~s}^{-1}$ e $1,34 \mathrm{~m} \mathrm{~s}^{-1}$ respectivamente.

\section{RESULTADOS E DISCUSSÃO}

\section{Operação de escarificação}

No histograma da Figura 2 são apresentados os resultados referentes à operação de escarificação para o tratamento A1. A profundidade variou de 0,1 a $0,4 \mathrm{~m}$ e a maior ocorrência foi $0,20 \mathrm{~m}$, enquanto o padrão da operação, estipulado pelos técnicos, era entre 0,20 e $0,25 \mathrm{~m}$. Os dados aceitáveis dentro da área obtiveram $34,0 \%$ do total apresentado.

Em A2, houve uma diminuição na variação; o intervalo foi de 0,15 a $0,325 \mathrm{~m}$, com concentração de pontos em 0,20 m (Figura 3). Com as regulagens e o controle realizados durante a operação, observou-se que as modificações efetuadas causaram uma concentração maior dos dados dentro do padrão desejado com 55,9\% da freqüência relativa nos limites de especificação. Houve redução de $38,4 \%$ na variabilidade dos dados (número de classes), e um aumento de $45,0 \%$ no número de pontos amostrados com valores $0,25 \mathrm{~m}$.

Analisando-se a carta de controle para a área $A 1$, verifica-se que a média encontrada foi $0,23 \mathrm{~m}$ para os pontos amostrados (Figura 4). Do total de 15 grupos, os quais variaram de 0,19 a $0,26 \mathrm{~m}, 4$ estão fora dos padrões especificados para a operação. Apesar disso, o processo encontra-se dentro de controle estatístico, o que significa não haver a existência de causas externas (especiais) ao processo interferindo no mesmo como por exemplo a mudança de operador, trator, tipo de solo ou métodos durante a operação.

Em A2, a variação dos dados foi menor, indo de 0,21 a $0,25 \mathrm{~m}$, com média de $0,23 \mathrm{~m}$ também. Nenhum grupo de pontos encontrou-se fora dos limites de especificação escolhidos pelo corpo técnico (Figura 5).

Quanto à amplitude dos dados, diferença entre o maior e o menor valor obtido, no tratamento $\mathrm{A} 1$ a média foi $0,10 \mathrm{~m}$ entre os grupos; em $\mathrm{A} 2$ a média foi $0,05 \mathrm{~m}$, ou seja, houve uma redução de $50 \%$ na amplitude dos dados com a realização do controle da operação. Entretanto, a comparação de médias das áreas realizada através do teste $T$ revelou que as parcelas não diferiram estatisticamente, não comprovando as informações. Os dados considerados são valores médios entre a profundidade medida na direção da haste do escarificador e a medida entre as hastes (Tabela 1).

A análise dos histogramas revela porém que a distribuição dos dados ocorreu de forma multi-modal na área $\mathrm{A} 1 \mathrm{e}$ bi-modal na $\mathrm{A} 2$. Onde a haste do implemento atuou, obteve-se uma maior profundidade quando comparado ao espaço entre as hastes no solo, onde a mobilização foi realizada pelo efeito de interferência, razão pela qual optou-se também por avaliar as duas situações independentemente. Para confirmar a segregação de dados visualizada nos histogramas, foi aplicado o teste $T$ para analisar os dados provenientes das medições de profundidade na linha de preparo e na entrelinha. Os resultados comprovam que existe diferença estatística entre esses dois grupos medidos, tanto no tratamento A1 como em A2 (Tabela 2).

\section{Linha de preparo do solo}

Para o tratamento A1 (Figura 6), a média encontrada foi de $0,29 \mathrm{~m}$ para os pontos amostrados, e do total de 15 grupos, os quais variaram de 0,24 a 0,32 $\mathrm{m}$, apenas 2 estavam dentro dos padrões especificados para a operação. Apesar disso, o processo encontrouse dentro de controle. Em A2, a variação dos dados foi menor, indo de 0,24 a 0,28 m, com média de 0,26 m, mas ainda 3 grupos de pontos encontraram-se fora dos limites de especificação determinados pelo corpo técnico (Figura 7). A implantação do controle, apesar de não satisfazer os padrões desejados, aproximou a médias dos dados mais próxima ao limite superior especificado, reduzindo-a em $10,3 \%$.

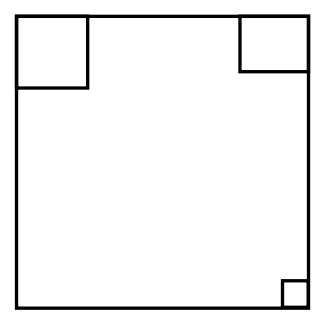

Figura 1 - Esquema do dispositivo criado para a medição do tamanho dos torrões nas áreas analisadas.

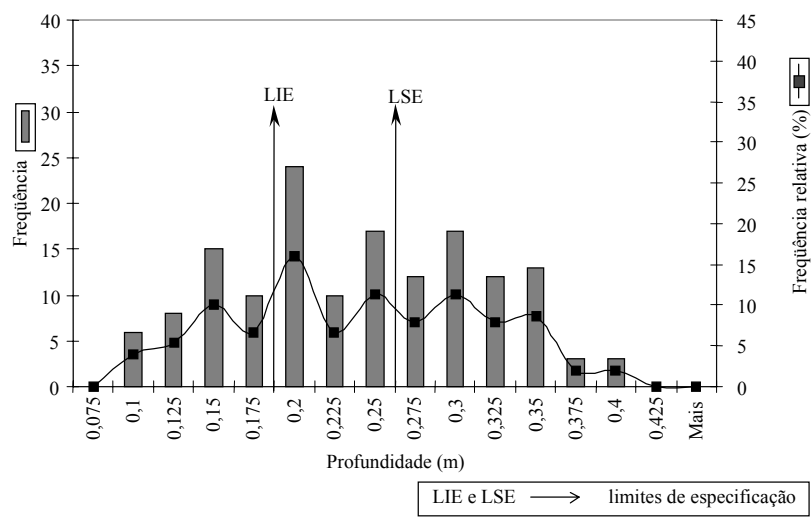

Figura 2 - Histograma de distribuição da profundidade de escarificação em A1.

Tabela 1 - Análise estatística (teste T) para os dados da operação de escarificação.

\begin{tabular}{ccccc}
\hline Tratamento & Média & Desv. Padr. & Prob $>|\mathrm{T}|$ & \\
\hline A1 & $0,229 \mathrm{~m}$ & 0,0761 & 0,0001 & $\mathrm{~A}$ \\
$\mathrm{~A} 2$ & $0,229 \mathrm{~m}$ & 0,0464 & 0,0001 & $\mathrm{~A}$ \\
\hline
\end{tabular}


A média encontrada de amplitudes entre os grupos em $\mathrm{A} 1$, foi de $0,12 \mathrm{~m}$, com controle superior de $0,30 \mathrm{~m}$. Para $\mathrm{A} 2$, houve uma menor variação de valores, com média atingida de 0,067 m. Desse modo, o controle resultou em uma redução média da amplitude dos dados dentre os grupos de $44,2 \%$. Novamente, verificou-se que houve uma redução da variabilidade de dados de profundidade dentro das áreas amostradas.

Os pontos da malha, dentro do intervalo desejado pelo corpo técnico, aumentou de $76,5 \%$ sendo que somente para a profundidade $0,25 \mathrm{~m}$, o ganho com a aplicação do controle foi de $109,1 \%$. A Tabela 3 confirma as diferenças estatísticas encontradas nas cartas de controle.

\section{Entrelinha de preparo do solo}

Para $A 1$, a média encontrada foi de $0,17 \mathrm{~m}$ para os pontos amostrados, e do total de 15 grupos, os quais variaram de 0,13 a $0,22 \mathrm{~m}$, apenas 3 estiveram dentro dos padrões especificados para a operação (Figura 8). Apesar disso, o processo encontrou-se dentro de controle. Em A2, após as mudanças implementadas, a variação dos dados foi menor, indo de 0,17 a $0,22 \mathrm{~m}$,

Tabela 2 - Análise estatística (teste T) para os dados coletados na linha de preparo do solo e na entrelinha, na operação de escarificação.

\begin{tabular}{cccccc}
\hline Tratamento & Medição & Média & Desv. Padr. Prob $>|T|$ & \\
\hline \multirow{2}{*}{ A1 } & Linha & $0,288 \mathrm{~m}$ & 0,0511 & 0,0001 & $\mathrm{~A}$ \\
& Entrelinha & $0,172 \mathrm{~m}$ & 0,0471 & 0,0001 & $\mathrm{~B}$ \\
\hline \multirow{2}{*}{ A2 } & Linha & $0,261 \mathrm{~m}$ & 0,0289 & 0,0001 & $\mathrm{~A}$ \\
& Entrelinha & $0,197 \mathrm{~m}$ & 0,0278 & 0,0001 & $\mathrm{~B}$ \\
\hline
\end{tabular}

Tabela 3 - Análise estatística (teste T) para os dados da operação de escarificação, na linha de preparo do solo.

\begin{tabular}{ccccc}
\hline Tratamento & Média & Desv. Padr. & Prob $>|\mathrm{T}|$ & \\
\hline A1 & $0,288 \mathrm{~m}$ & 0,0511 & 0,0001 & $\mathrm{~A}$ \\
A2 & $0,261 \mathrm{~m}$ & 0,0289 & 0,0001 & B \\
\hline
\end{tabular}

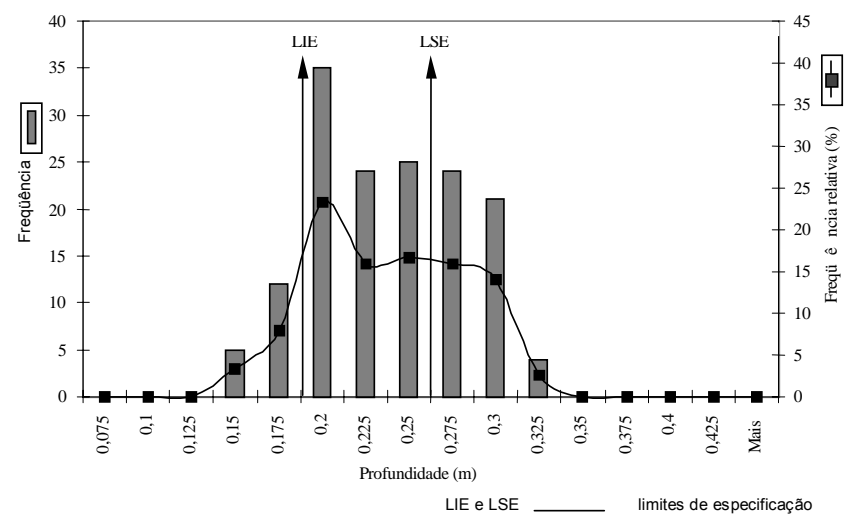

Figura 3 - Histograma de distribuição da profundidade de escarificação, em A2. com média de $0,20 \mathrm{~m}$. Apesar de 7 grupos de pontos se encontrarem fora dos limites especificados para a operação, de 0,20 a $0,25 \mathrm{~m}$, os 15 grupos variaram menos em torno da média, ainda estando dentro de controle estatístico (Figura 9).

A implantação do controle, apesar de não satisfazer os padrões desejados pelos técnicos, aumentou os valores médios em $15,3 \%$. No tratamento $A 1$, a média encontrada de amplitudes entre os grupos foi de $0,10 \mathrm{~m}$. Já para A2, observou-se uma menor variação de valores, com média de 0,05 m. Houve uma redução média da amplitude dos dados dentre os grupos de $46,0 \%$, diminuindo a variabilidade do trabalho realizado.

A amplitude da profundidade variou de 0,1 a 0,3 $\mathrm{m}$ e a maior ocorrência encontrada em $\mathrm{A} 1$ foi a profundidade de $0,20 \mathrm{~m}$, enquanto que a recomendação (padrão) da operação era que a mesma fosse efetuada entre 0,20 e $0,25 \mathrm{~m}$. Os dados aceitáveis dentro da área obtiveram $45,3 \%$ do total apresentado. Em A2 ocorreu uma diminuição da amplitude, a qual variou de

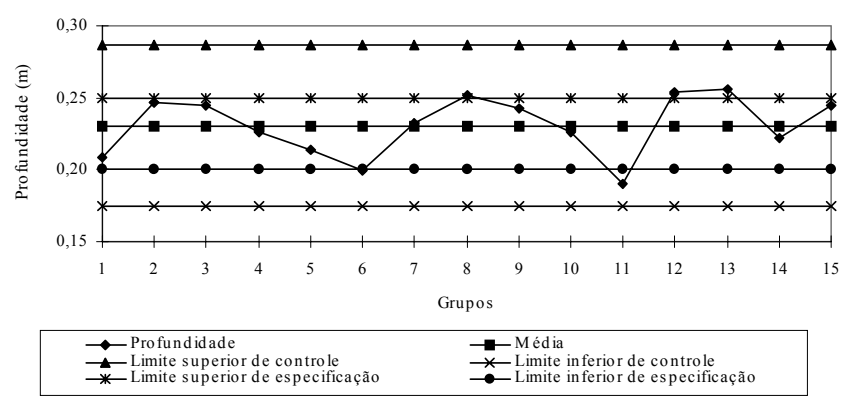

Figura 4 - Carta de controle com médias, para a operação de escarificação em A1.

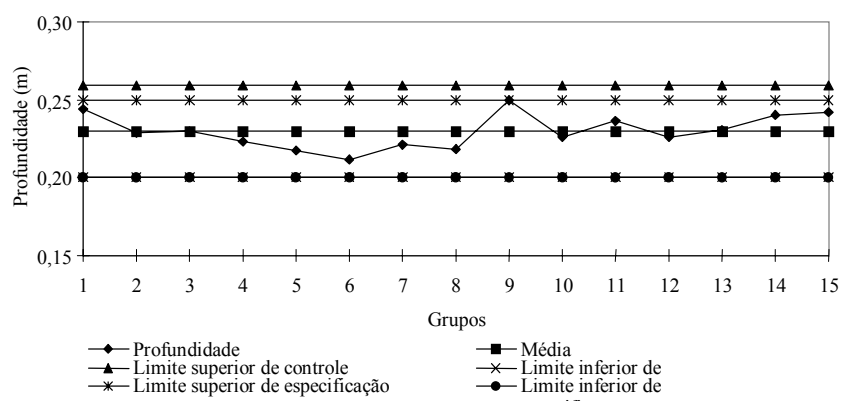

Figura 5 - Carta de controle com médias, para a operação de escarificação, na área A2.

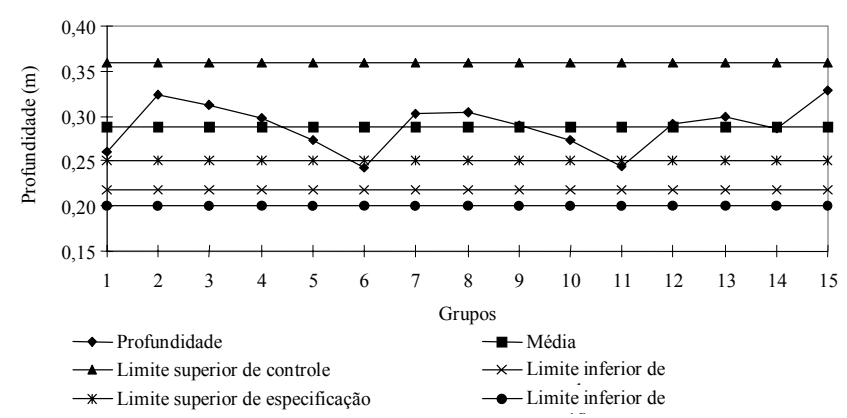

Figura 6 - Carta de controle com médias, para a operação de escarificação, na linha de preparo do solo, em A1. 
0,15 a $0,30 \mathrm{~m}$, com concentração de pontos em 0,20 m. Comparando-se ambos, as modificações efetuadas causaram uma concentração maior dos dados ao redor do valor desejado com $72,0 \%$ da freqüência relativa.

A melhoria com a introdução das técnicas de controle resultou em um aumento de $58,9 \%$ dos pontos da malha dentro do intervalo desejado. A Tabela 4 confirma as diferenças estatísticas anotadas nas cartas de controle e histogramas.

\section{Operação de gradagem}

$\mathrm{Na}$ operação de gradagem, referente ao tratamento $\mathrm{A} 1$, a dimensão dos torrões variou de 0,004 a $0,009 \mathrm{~m}$ e a maior ocorrência encontrada foi o diâmetro de 0,07 m enquanto que a recomendação (padrão) da operação era que fosse menor do que $0,04 \mathrm{~m}$ (Figura 10). Os dados aceitáveis dentro da área obtiveram $5,3 \%$ do total apresentado.

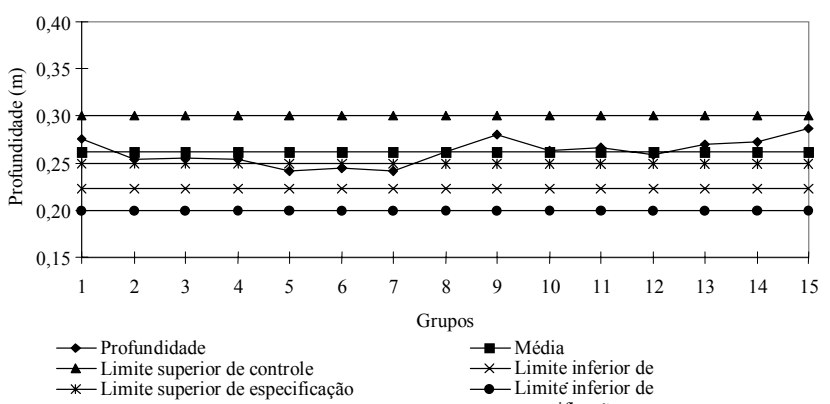

Figura 7 - Carta de controle com médias, para a operação de escarificação, na linha de preparo do solo, em A2.

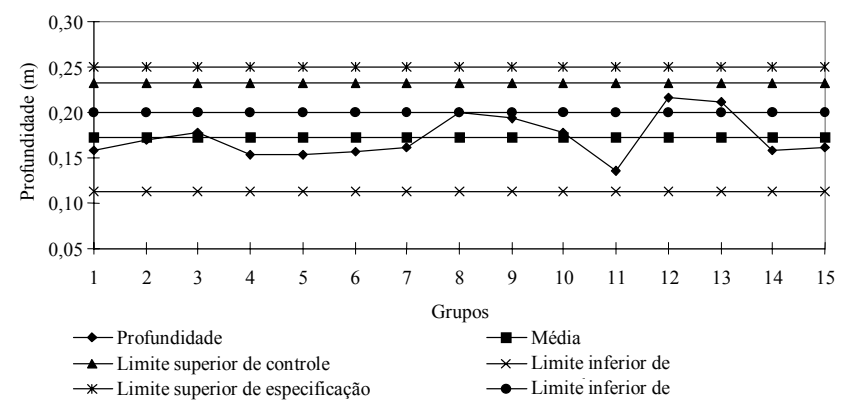

Figura 8 - Carta de controle com médias, para a operação de escarificação, na entrelinha de preparo do solo , no tratamento $\mathrm{A} 1$.

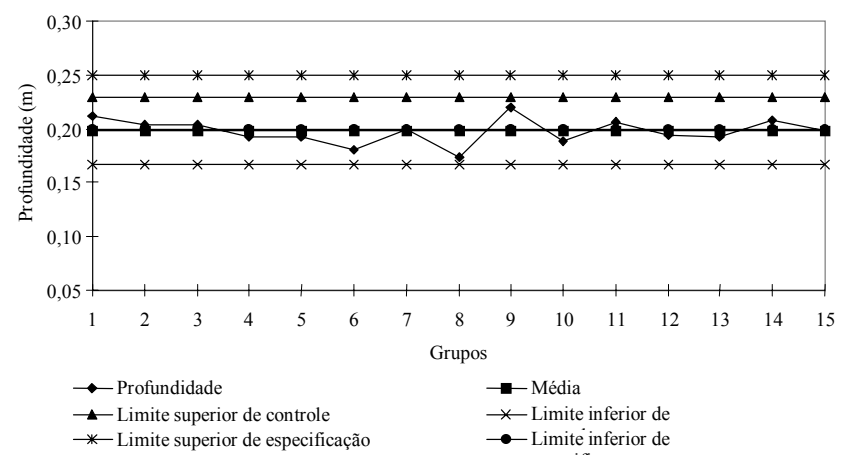

Figura 9 - Carta de controle com médias, para a operação de escarificação, na entrelinha de preparo do solo, no tratamento $\mathrm{A} 2$.
No tratamento A2 (Figura 11) observa-se um aumento dos valores desejados com a concentração de pontos em $0,07 \mathrm{~m}$. Pela comparação dos histogramas, as modificações efetuadas causaram uma concentração maior dos dados ao redor do valor desejado com $9,3 \%$ da freqüência relativa, dentro do intervalo delimitado pelos limites de especificação.

No tratamento A1 (Figura 12), a média de tamanho de torrões foi de $0,07 \mathrm{~m}$ para os pontos amostrados, e do total de 15 grupos, os quais variaram de 0,06 a $0,08 \mathrm{~m}$, nenhum esteve dentro dos padrões especificados para a operação, que foi torrões com diâmetros menores que $0,04 \mathrm{~m}$. Apesar disso, o processo encontrou-se dentro de controle.

Em A2 (Figura 13), após a implementação do controle, a variação dos dados foi menor, indo de 0,05 a $0,07 \mathrm{~m}$, com média de $0,06 \mathrm{~m}$. Apesar de ainda não observar-se grupos dentro das especificações desejadas, a operação encontrou-se dentro de controle estatístico. A implantação do CEP, apesar de não satisfazer os padrões desejados, reduziu os valores médios em $9,8 \%$.

Tabela 4 - Análise estatística para os dados da operação de escarificação, na entrelinha de preparo do solo.

\begin{tabular}{ccccc}
\hline Tratamento & Média & Desv. Padr. & Prob $>|\mathrm{T}|$ & \\
\hline A1 & $0,172 \mathrm{~m}$ & 0,0289 & 0,0001 & A \\
A2 & $0,197 \mathrm{~m}$ & 0,0511 & 0,0001 & B \\
\hline
\end{tabular}

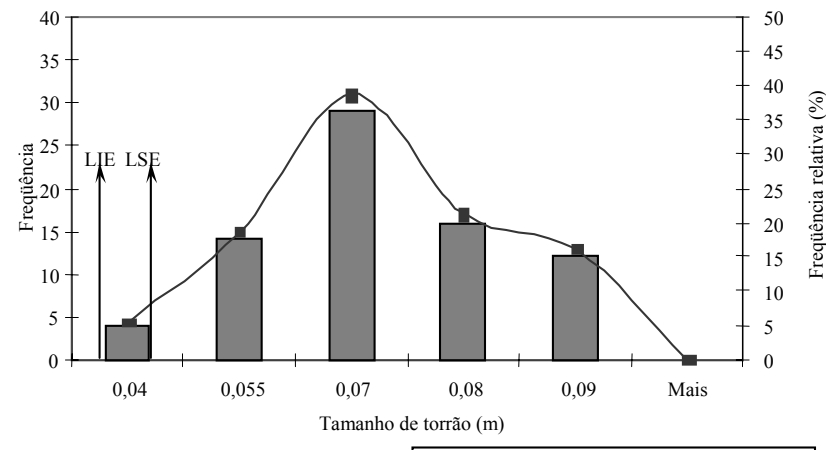

LIE e LSE $\longrightarrow$ limites de especificação

Figura 10 - Histograma de distribuição do tamanho de torrões, na gradagem, em A1.

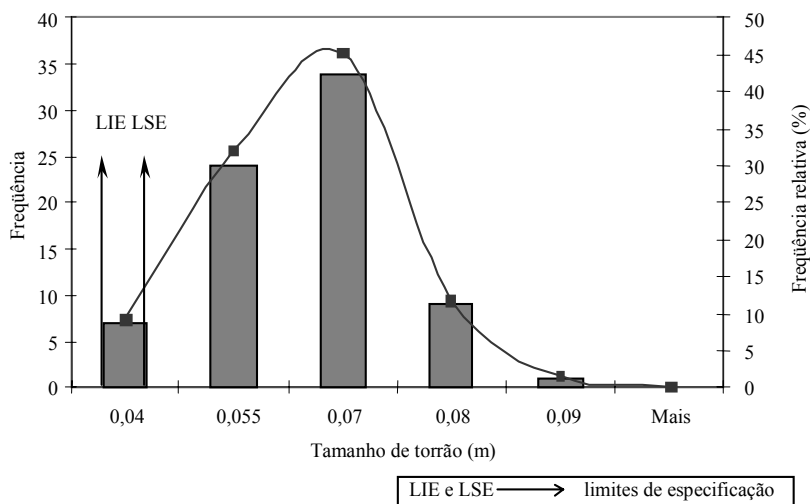

Figura 11 - Histograma de distribuição do tamanho de torrões, na gradagem, em A2. 
Tabela 5 - Análise estatística (teste T) para os dados da operação de gradagem.

\begin{tabular}{ccccc}
\hline Tratamento & Média & Desv. Padr. & Prob $>|T|$ & \\
\hline A1 & $0,071 \mathrm{~m}$ & 0,0122 & 0,0008 & A \\
A2 & $0,065 \mathrm{~m}$ & 0,0106 & 0,0009 & B \\
\hline
\end{tabular}

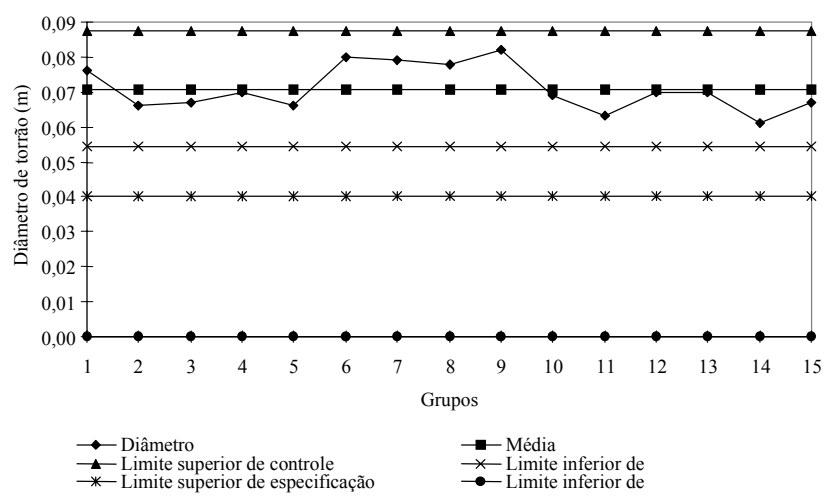

Figura 12 - Carta de controle com médias, para a operação de gradagem em A1.

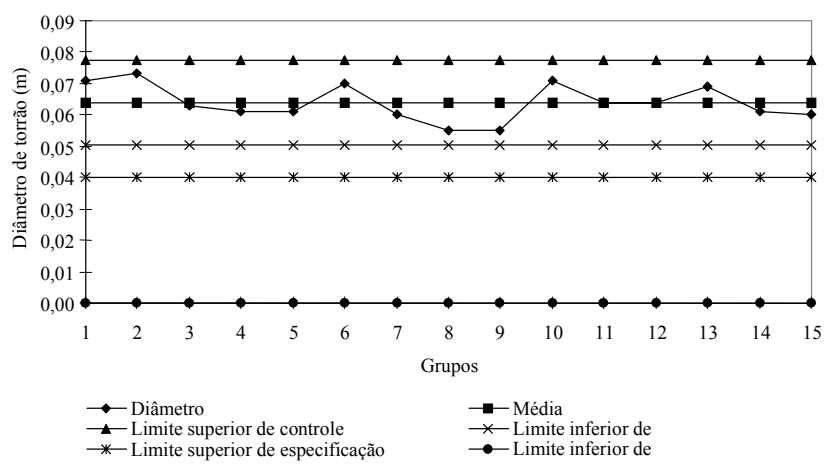

Figura 13 - Carta de controle com médias, para a operação de gradagem, em A2.

A melhoria com a introdução do controle resultou em um aumento de $75,0 \%$ dos pontos da malha dentro do intervalo desejado pelo corpo técnico. Houve uma redução do número de torrões de diâmetro de $0,09 \mathrm{~m}$ em $91,7 \%$. A Tabela 5 confirma as diferenças estatísticas mostradas nas cartas de controle e histogramas.

\section{CONCLUSÕES}

O controle das operações agrícolas permitiu a diminuição na variabilidade obtendo-se resultados mais próximos aos especificados pelo corpo técnico.

$\mathrm{Na}$ escarificação, a introdução do controle ocasionou um aumento de $34 \%$ para $55 \%$ de dados dentro dos limites de especificação desejados, embora sem diferença estatística entre as médias para a situação sem e com controle. Existe diferença na escarificação para a profundidade de preparo entre as médias da linha (passagem da haste) e entre linhas (mobilização pelo efeito interferência). Quando os tratamentos sem e com controle são avaliados, as profundidades para a linha e entre linha diferem revelando o melhor resultado obtido com o controle da operação.

Para a operação de gradagem ocorreu redução de $9,8 \%$ dos dados médios de tamanho de torrões e um aumento de $75 \%$ de torrões aceitáveis, controlando-se a operação.

A implantação do controle nas operações foi viável e adequado ao sistema de produção em questão.

\section{AGRADECIMENTO}

À Coordenação de Aperfeiçoamento de Pessoal de Nível Superior (CAPES), pela oportunidade dada na realização deste trabalho.

\section{REFERÊNCIAS BIBLIOGRÁFICAS}

BONILLA, J.A. Métodos quantitativos para qualidade total na agricultura 2.ed. Contagem: Líttera Maciel, 1995. 250p.

DODSON, M.S. Avaliação da influência de indicadores de qualidade no custo operacional de um sistema de produção de milho (Zea mays L.): estudo de caso da semeadura. Jaboticabal, 1998. 80p. Monografia (Graduação) - Faculdade de Ciências Agrárias e Veterinárias, Universidade Estadual Paulista "Julio de Mesquita Filho".

FERNANDES, R.A.T. Gerenciamento da qualidade em operações agrícolas mecanizadas em um sistema de produção de cana-de-açúcar (Saccharum spp.). Piracicaba: USP/ESALQ, 1997. 66p. (Relatório final)

LINO, A.C.L.; PECHE FILHO, A.; STORINO, M. Análise da fragmentação de fitomassa realizada por uma roçadora em área com predominância de capim-colonião. Bragantia, v.58, p.401-407, 1999.

LOPES, M.B.; MILAN, M.; COELHO, J.L.D. Qualidade em operações agrícolas mecanizadas na cultura de cana-de-açúcar. Stab: Açúcar, Álcool e Subprodutos, v.13, p.26-30, 1995.

MONTGOMERY, D.C. Introduction to statistical quality control. 5.ed. New York: John Wiley \& Sons, 1996. 677p.

Recebido em 27.12.00 